\title{
The Implementation of ISSECI Model for Enhancing Thai EFL Students' Intercultural Pragmatic Competence: Politeness Strategies
}

Wapee KONG-IN*, Anamai Damnet

Faculty of Liberal Arts and Sciences, Kasetsart University, Kampaengsaen Campus, Nakhonpathom, Thailand

Corresponding Author: Wapee Kong-in, E-mail:sirima.apicharin@gmail.com

\author{
ARTICLE INFO \\ Article history \\ Received: January 19, 2018 \\ Accepted: March 28, 2018 \\ Published: June 30, 2018 \\ Volume: 9 Issue: 3 \\ Advance access: May 2018 \\ Conflicts of interest: None \\ Funding: The research is financed by \\ Office of the Higher Education \\ Commission of Thailand.

\section{Keywords:} \\ Intercultural Pragmatic Competence, \\ Politeness Strategies, \\ Knowledge Management, \\ English as a Foreign Language, \\ Perception
}

\begin{abstract}
Regarding pedagogical purpose, Thai EFL learners' communicative English proficiency is obviously restricted by the limited experiences of L2 politeness strategies. The aim of the current study is to investigate the effectiveness of the innovative teaching, ISSECI Model in terms of intercultural pragmatic competence: face threatening ace (FTA) - Do FTA and Don't do FTA. The twenty Thai EFL undergraduate students from Rajabhat University were selected as participants through simple random sampling. Data were collected using rejoinder-discourse completion task mixed with open time free response construction, and was statistically analyzed in MEAN, standard deviation, and t-test. The findings revealed that the participants' intercultural pragmatic competence after learning through ISSECI Model is significantly higher than that before the experiment $\left({ }^{*} p<0.05\right)$. The participants' perception with regard to ISSECI Model included four domains, i.e., English knowledge gained, cultural awareness, strengths, and weaknesses of the model.
\end{abstract}

\section{INTRODUCTION}

In Thailand, English is employed for exclusive or specific purposes, e.g., technology, employment, and face-to-face communication with foreigners rather than use in daily life, especially for the broader communication in the society. According to Article 34 of the ASEAN Charter, English is acclaimed to be the working language of ASEAN (The ASEAN Secretariat, 2008: 29). Moreover, ASEAN Economic Community (AEC 2015) requires regional connection of South-East Asian countries for the sake of mutually economic, social, cultural, and educational advantages. Hence, Thai people cannot avoid using English for contacting with the foreigners. This mutually macro-agreement confirms that communication in English contributes to crossover from one frontier to the other for global cooperation (Jenkins: 1996). However, this international cooperation cannot guarantee the improvement of Thai's poor L2 exposure because of the hindrance of educational facilitation.

L2 exposure, apart from daily-life communication, is considerably vital to language learning in the classroom setting. The explicit input, or language exposure in the classroom plays an important role in learners' L2 development (Blum-Kulka \& Olshtain, 1986; Bardovi-Harlig \& Hartford, 1993; Bouton, 1994). Yet, the achievement in L2 learning is limited by small chance of the students to have an exposure to English commu- nicative situations in compulsory English classes in Thailand (Khamkhien, 2010; Poonpon, 2011), besides background of English proficiency that makes advancing English lessons difficult (Chayanuvat, 2007). This fact is supported by Damnet (2008:2) who stated that such a problem is a consequence of the constraint of intercultural contact as follows.

In Thailand, even today, English clearly has the status of a foreign language and the majority of Thai learners of English even at university level have had no or very limited contact with native speakers of English.

The recent revolutionary campaign of changing English status from EFL to ESL (English as a Second Language) by Ministry of Education is not successful on account of controversy caused by social sensitivity and non-colonization background of the country. Later, English is ranked as primary or preferred foreign language beyond compare (Wongsothorn, 2000). This foreign language is assigned as a compulsory subject in national curriculum of Thailand at all level of education. It has been pedagogically recognized as 'English as a Foreign Language' (EFL). This status is corresponding to the definition given by Kirkpatrick (2007: 27) as English is not actually used or spoken very much in the normal course of daily life, but is learned at school (China, Indonesia, Japan, countries in the Middle East) Skutnabb-Kangas (2000) 
uses the term 'submersion' to technically refer to teaching English in the society where students learn and use it as a foreign language. This submersion includes Thai teachers' instruction to which English remains as EFL. To put it in the other word, teaching method of Thai teachers who are not familiar with English might have a negative effect on Thai learners' English proficiency.

In the circle of Thai education, translation method has been proven as the cause of learners' communicative problem for over the last three decades (Intaraprawat, 1978; Prasarnsap, 1999). Teaching grammar helps the learners use language correctly, but never guarantees the achievement in intercultural communication. This practice signals the separation of teaching two parts of the language: linguistic competence and communicative competence. Since the higher degree of teaching grammar is provided to the learners, the interactive performance can be restricted. The typical teaching method is the origin of L2 learners' limitations in interactive skills, and obstacle of their management of effective communication (Ellis, 1999). Consequently, their intercultural competence is not enough extended as it should as Brislin (1997: 94) posits:

...Many students have not had significant intercultural experiences in

Their lives so have had a difficult time conceptualizing the fact that

Many people have been socialized into a different culture.

Social interaction in a various contexts is a necessary skill to help learners achieve better communicative competence (Bachman \& Palmer, 1996; Alptekin, 2002; Trenholm and Jensen, 2004). The obsolescent grammar teaching can be, therefore, harmful to the students' perception of English in communicative use (Myhill \& Watson, 2012). Without sufficient exposure to the social contexts, many Thai students cannot apply their grammatical knowledge to their real life intercultural communication. Basically, natural language acquisition and knowledge accumulation are indeed the key factors leading to success in language use. An array of approaches are introduced to assist their learning English, such as, CLT, CALL, task-based learning, peer-assisted method, etc., but none of them focus on combination between theories such as SLA theory and KM and cannot guarantee learning achievement in terms of intercultural pragmatic competence on account of some limits.

Seeking innovative teaching for language competence development of Thai EFL learners in line with second language acquisition in association with knowledge management is a new challenge of educators. "ISSECI" model is, therefore, designed to fulfill this mission. This model is developed in combination between two related theories: second language acquisition (SLA) and knowledge management (KM). The ISSECI Model stands for Input, Scaffolding, Socialization, Externalization, Combination, and Internalization.

The input that learners perceive from controlled environment contribute to using language correctly in the first place before the connection between trained behavior to automatic use in the future, or the implicit replacement. Related to such a principle, Krashen's Input Hypothesis can be alternatively applied. The teachers need to make sure that input given to the learners stay comprehensible sufficiently so that they can continue to the next step of using language more effectively, the so-called $i+1$ hypothesis (Krashen, 1985). Furthermore, learners' competence are ready to be developed not only by their own determination, but also with scaffolding, or the assistance or guidance of the experienced or more skillful persons, e.g. teachers, peers, and other concerning parties. Hence, the concept of $Z P D$ - Zone of proximal development introduced by Vygotsky (1978) is another component playing an important role in language development system.

The other related approach to promote L2 acquisition refers to searching for the knowledge for further internalization and natural application, or knowledge management (KM). It was initially proposed by Nonaka \& Takeuchi (1995) corresponds this rationale suitably. It consist of four stages of learning process based on 'a spiral' creation and transform of knowledge from tacit to explicit prior to the new tacit knowledge (See (Nonaka et. al. 1994): (1) Socialization sharing mutual interest or learning goal (tacit-to-tacit); (2) Externalization - drawing tacit knowledge explainable to the others through exchange of experiences and restoring it in the various forms of documentation, e.g. hard copies and soft copies (tacit-to-explicit); (3) Combination - assembling and disseminating the categorized tacit knowledge (explicit-to-explicit) and; (4) Internalization - connecting explicit knowledge gained from combination stage with application through assigned tasks so that the knowledge is embodied as a part of individual tacit knowledge (explicit-to-implicit).

At the beginning stage of ISSECI model, comprehensible input and scaffolding is initially applied to provide the learners with foundation of necessary linguistic knowledge and skills before the involvement in KM-oriented learning activities to help them capture the extracted tacit knowledge in the real communicative situation, particularly with native speakers, for forming explicit knowledge documentarily, and construct their own tacit knowledge at the final stage.

Many studies were conducted to confirm particular approaches' strengths contributing to learners' English learning development. However, most of them are still far from the examination of integrated theoretical concepts to promote learners' intercultural pragmatic competence. Once the implementation of the model is complete, it's challenging to find change of Thai EFL students' intercultural pragmatic competence and to describe how such a model has an effect on their English learning and application.

\section{RESEARCH OBJECTIVE}

The current study aims to investigate the effectiveness of the innovative teaching, ISSECI Model in terms of intercultural pragmatic competence: face threatening ace (FTA) - Do FTA and Don't do FTA via comparison between pretest and posttest results of Thai EFL students' intercultural pragmatic competence. The hypothesis of the research is set as "Will the participants' posttest results be higher than those of the pretest or not?" Further, the perception of the participants with regard to enhancing their intercultural pragmatic competence through ISSECI Model is qualitatively studied. 


\section{REVIEW OF LITERATURES}

\section{Politeness Strategies: FTA}

Linguistic politeness is widely defined as use of controlled language by human to maintain the positive relationship among them by caring for each other's face and avoiding conflict (Watts, 2003; Janney \& Arndt, 2003). Self-identity represented by 'Face' - the public image of a person want to maintain with social acceptance (Goffman,1967). Actually, one can either experience face loss or maintenance in general social interaction (Bowe and Martin, 2007). It is recommended to use language carefully taking face wants of the hearers into consideration. The face wants, as explained by Brown \& Levinson (1987), consist of negative face wantthe desire to exclude the others' interruption in one's action or self-esteem, and positive face want-the desire to be accepted by the others as a group member who share the same interests. These face wants encourage the speakers to lessen face threatening by choosing the alternative way of communication instead of straightforward form of language so that the hearers will not be uncomfortable (Ungureanu, 2004). Of all factors affecting communication regarding selection of linguistic politeness, social distance plays an important role in help speakers and hearers decide what kind of meaning conveyance should be created. It is an abstract aspect of non-verbal communication which develop other human' related structures (Harrison et al., 1972).

According to Brown \& Levinson (1987: 74-84), social distance, power and ranking of imposition, are crucial factors of speculating the seriousness or weightiness for choosing the appropriate politeness strategy for evasion of face-threatening act (FTA). The two classes of such a strategy delineates Do FTA and Don't do FTA. The former includes two sub-set categories - on record and off record. Within on record, there are four methods to express linguistic politeness i.e. without redressive action, or baldly; with redressive action, or use of mitigating device ${ }^{1}$ (Deepadung, 2009: 144); positive politeness; and negative politeness. On record is defined as use of indirectness or vagueness. The latter means strategic meaningful silence. The samples below elaborate these terminology in the sense of application (Table 1).

\section{Thai EFL Students' Intercultural Pragmatic Competence}

Chiravate (2011)'s study reveals a noticeable difference between use of politeness strategies by native English speakers and Thai EFL learners. Based on her findings, the difficulty in acquiring intercultural pragmatic competence can be explained by two reasons-unawareness of influential social factors and L1 pragmatic knowledge shift. Chiravate examines Thai learners' politeness strategies on basis of social and psychological distance as well as closeness in four categories: socially and psychologically distant (students-elderly distinguished professor), socially distant and psychological close (students-young professor), socially and psychological close (two long-time close friends), and socially close, but psychologically distant (two classmates who do not get close to each other, or one dislikes the other). It is found that less polite strategies are significantly used by Thai learners. In the light of relationship between social distance and pragmatic competence, her findings indicate that Thai learners cannot employ the politeness strategy as similarly as the native speakers. Although they request their close friend to do something, the native speakers adopt the moderate strategy, such as, "Can you...?" while direct imperatives are mostly produced by Thai learners in the same situation.

Chiravate claimed that the aforementioned difference in politeness strategies is an implicit evidence of L1 interference of Thai request paradigm for closeness relationship to English communication ( $c f$. the influential use of final particles, i.e.,__noi/or/_si/for direct request in Thai studied by Khahua, 2003). The more polite expression is normally employed, in Thai society, when interacting with strangers or interlocutors with low-intimacy (Khanittanan, 1988).

\section{Krashen's Input Hypothesis}

In the 1980s, Krashen developed a set of well-known 6 SLA hypotheses which are the foundation of natural approach of learning, which underlines the relationship between natural learning process and spoken production, introduced by Krashen and Terrell (1983). After Krashen (1981: 6-7), the most powerful method to develop language acquisition is the provide the meaningful input within the natural setting of communication as he explains as follows. This hypothesis is originated from the determination of Krashen to answer the question "How do we acquire language?" This puzzle is initially to be solved by parameter $i+1$. Krashen contends that learners have their own hierarchical steps of language development from one to the other upper level. When $i$ represents the current competence, co how can we move upwards to $i+1$ ? The possible solution is the understanding of the given input rather than the language form. In other words, one can attain the level of $i+1$, which remains too complex to understand and still beyond their actual competence, using additional non-linguistic aids, such as, contextual clues, knowledge of the world, and other extra-linguistic information. The sequential processes of input hypothesis can be concluded with the following 4 statements.

(1) It has nothing to do with the peripheral boundary of 'learning', but it is a matter of central domain of ' $a c$ quiring'.

(2) Acquiring language means understanding language, which starts from $i$, the present

Limited ability to understand language meaning. Contextual and extra-linguistic information, hence, plays important role to help the acquirer to overcome the problem.

(3) After the difficult meaning of the language is understood using the clues in (2), that means the acquirer automatically reaches $i+1$ level.

(4) Acquirer can effectively produce their own intelligible language after all without learning directly.

\section{Scaffolding Instruction}

Vygotsky (1978)'s zone of proximal development (ZPD) is an approach to prepare the learners to be able to learn and achieving in solving problems in real life communication. 
Table 1. Use of politeness strategies of do FTA and don't do FTA

\begin{tabular}{lll}
\hline Strategies & Language patterns & Sub-strategies \\
\hline & On record & Without redressive action \\
& (1) Mind your step & With redressive action \\
& (2) Bob, give me a piece of paper, please. & Positive politeness \\
Do FTA & (3) May I have a glass of water? & Negative politeness
\end{tabular}

(5) Who took my pen? and how can I finish the essay?

Don't do FTA Use of non-verbal language - bodily movement or action for particular purpose such Meaningful silence as searching for something until it is noticed by the others

Source: Adapted from Brown and Levinson (1987: 69)

Then, scaffolding is a relevant technique to support such a theory. Wood et al. (1976: 98) define scaffolding as an interactional role between learners and teachers while providing helps related to the assigned tasks or problems, and learners' problem-solving skill is highly expected after the use of this technique. The assistances may come up with guidance, facilitations, or suggestions. The individual support is provided through the aiding strategy (Chang et al., 2002).

In learning languages, the knowledge to be gained embeds in part of scaffold or social support for the new perception. (Raymond, 2000: 176). Olson and Pratt (2000) suggest that scaffolding instruction should introduce the new tasks beyond the level of learners' actual ability to affirm that they cannot complete them alone by themselves, and this brings them to ZPD. The characteristics of scaffolding activities are studied by some scholars, such as, Bransford et al. (2000), McKenzie (2000) and Wood et al. (1976). The scaffolding activity characteristics applied to the present study can be synthesized as follows.

(1) Attracting learners' attention e.g. use of guiding question or real-life problems.

(2) Defining learning goal e.g. group discussion as a socialization to share the same goal of learning.

(3) Simplifying directions of activities e.g. explaining what learners need to do to achieve goal step by step.

(4) Reducing learners' frustration e.g. attempt to observe learners' difficulties and give pieces of advice if necessary or until all forms of frustration are cleared up.

(5) Providing feedback on learners' work e.g. work checking or exchange of ideas between teacher and learners for further improvements.

(6) Supporting learners' learning e.g. demonstration and giving other learning sources.

\section{Knowledge Management}

Based on theory of organizational knowledge creation, the most influential model which can be applied to teaching language is SECI Model (Nonaka and Takeuchi, 1995). They concede that knowledge is not in the consistent condition. Conversely, there is a conversion or spiral movement as crossover between the epistemological domain of explicit and tacit knowledge. Social interaction contributes to obtaining new knowledge through converting tacit to explicit knowledge and vice versa. This process leads to the growth of new knowledge indefinitely as shown in Figure 1.

The knowledge circulation of Nonaka and Takeuchi 1995 's KM model depends on searching for and creating knowledge within 4 stages as follows. Socialization is a transfer of tacit knowledge from one to the other, so tacit-to-tacit knowledge through the face-to-face interaction between groups or individuals. Exchange of knowledge and experiences occur at this stage without recording obviously. Externalization occurs when tacit knowledge begins to be elicited as explicit concept-tacit-to-explicit knowledge through comparison and analogy. Principles, thoughts, hypotheses, and model of effective practices for successful performance are formulated or summarized. Often, operational manual is an documentary outcome of this stage. Combination is defined as the dissemination of documentation gained from externalization stage via communicative network or information technology. Knowledge is shared and accumulated wider and this provides the learners to choose the best practice among new knowledge, so explicit-to-explicit knowledge. Internalization is established once knowledge asset is eventually formed after the knowledge is shared and learned-explicit-to-tacit knowledge. The knowledge becomes an individual innovation to be applied in professional life, i.e. skills and approaches to deal with problems.

In Thai context of educational purpose, few studies prove its cross-cultural applicability. The most relevant investigation refers to the study of Thammaraksa (2010) on how applying knowledge creating process "SECI" to teach a Fundamental English course improve Thai EFL learners' writing skill. Through the four modes of learning process, a multiple tasks are designed for full participation of the learners ranging from group discussion, interview with the experienced persons, compilation of knowledge from various sources up to production of innovation. The results show that the learners succeed in transferring the tacit knowledge to domain of explicit knowledge, and individual tacit knowledge at the last stage. Knowledge asset and innovation is expected to be obtained to reinforce self-directed learning.

As for another similar knowledge management applicability to Thai educational area, Onthanee (2008)'s research prove the relationship between knowledge management-based instructional model and learning facilitators' 


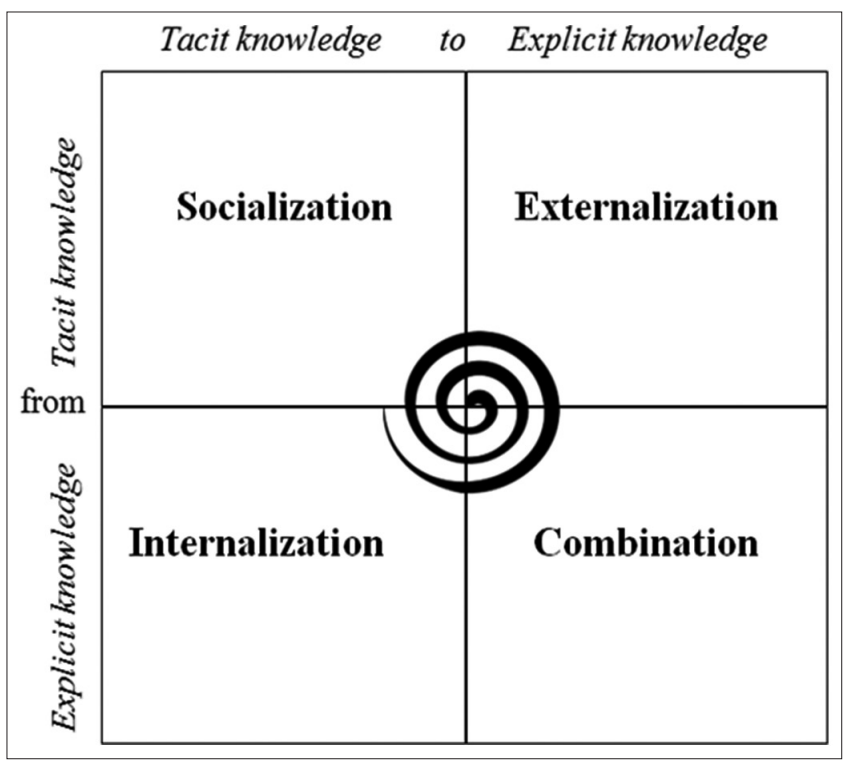

Figure 1. The spiral of knowledge formation

Source: Adapted from Nonaka and Takeuchi (1995)

competence of teacher students within seven processes: (1) knowledge identification (2) knowledge acquisition (3) knowledge creation (4) knowledge sharing (5) knowledge storage (6) knowledge transfer and (7) knowledge evaluation. Her findings reveal that the competence, skill, and attitude of the participants is higher apart from their high level of satisfaction towards the developed instructional model.

\section{METHODS}

\section{Participants}

The unit of analysis is identified as a total of twenty upperclassmen (the $3^{\text {rd }}$ year students) majoring in English from Faculty of Education at Bansomdejchaopraya Rajabhat University, Bangkok, Thailand. They are studying in the $2^{\text {nd }}$ semester of academic year 2015 (February-July 2016)-section ENG 561-1 from the total two sections arranged by office of academic promotion of the university. Drawing cast is the method for assigning randomly section ENG 561-1 as the research sample.

\section{Research Design}

In this study, one-group pretest and posttest design is adopted to find the causal relationship between independent variable (ISSECI Model) and dependent variables (intercultural pragmatic competence: politeness strategies). The experiment is implemented within sixteen weeks during semester 2/2015.

\section{Instruments}

\section{Rejoinder-DCT mixed with open time free response}

Characterized by its intercultural pragmatic competence assessment, the present study claims the use of rejoinder-discourse completion task mixed with open time free response construction for data collection based on the previous stud- ies, such as, Pinyo (2010), Pinyo, Aksornjarung, and Laohawiriyanon (2010), and Khamyod and Aksornjarung (2011) which employed adapted traditional written DCT rather than other forms, including role play and simultaneous speech data collection. The modified version of DCT in this study-a combination between rejoinder-type and open time free response construction is justified by the intrinsic nature of human communication under setting given and alternation of language choice both verbally and non-verbally. The data obtained from this method is, according to the research purpose and hypothesis, to be rated by native speakers to indicate the level of intercultural pragmatic competence of the participants. The twelve scenarios are set up to cover four groups of speech acts, namely assertives in scenarios 1-3 (e.g. disagreeing and claiming), directives in scenarios 4-6 (e.g. requesting and suggesting), commissives in scenarios 7-9 (e.g. offering and promising), and expressives in scenarios 10-12 (e.g. apologizing, greeting, thanking), with hidden social variables as a helping criteria to help decide which language forms should be selected. These scenarios are simulations of UK setting where use of Thai is totally prevented when contacting with foreigners without assistance from other Thais.

The 0-2 rubric, adapted from Cohen and Olshtain communicative ability scales in Cohen (1994), Pinyo (2010), Pinyo, Aksornjarung, and Laohawiriyanon (2010), and Khamyod and Aksornjarung (2011), is used for scoring the participants' intercultural pragmatic competence by three native English speaking raters in terms of the following four produced language characteristics: (1) Adequate and clear information, (2) Politeness as a reflection of related social factors, i.e. intimacy, seniority, and imposition affecting selection of language forms, (3) Near-native expression or idiomatic use, and (4) Linguistic errors, such as, pronunciation, vocabulary, and grammar, which cause hearers' misunderstanding of speakers' intention. Hence, the total scores of the test are twenty-four (total scores ' 2 ' for each item x 12 scenarios).

\section{Unstructured Interview Protocol}

To serve the qualitative objective of the study, the researcher employs a set of unstructured interview protocol to obtain perception toward pros and cons of learning through traditional model and ISSECI model-based activities from the participants. The purpose of using this method is to interpret the initial quantitative findings, stimulate new ideas, and observing satisfaction towards programs (Higgenbotham and Cox, 1979). This method is criticized for its limitation of data generalizability caused by dominance of few group members on responding direction. However, rich data can be gained from this method as well. The convergence between verbal and non-verbal response can be easily observed since within the live context of data collection (Stewart et al., 2007). The questions include the followings.

(1) Do you think that your English knowledge is increased after the research project is complete? How? Why or why not? 
(2) Did you learn anything about cultural aspects in English conversation after participating in research project? If so, what are they?

(3) What are the strengths of the teaching method of research project you experienced?

(4) Do you find any drawbacks of learning through the teaching method you experienced? If so, what are they?

\section{Data Analysis}

As the objective of this research navigates the quantitative data analysis, descriptive statistics, i.e. arithmetic mean and standard deviation are consequently used to explain the overview of participants' ICPC competence, integrated speaking skill, and their L2 learning motivation. The referential statistic $t$-test is used to compare the mean of pretest and posttest results of Thai EFL's intercultural pragmatic competence with alpha labeled at 0.05 .

Qualitative data analysis of the present study depends on Strauss and Corbin (1998) and Corbin and Strauss (2008)'s coding technique which incorporate three coding stages: open coding-finding the repetition of data; axial codingspecifying sub-categories and theme relation; and selective coding-summarizing the final themes and their related subthemes.

\section{RESULTS AND DISCUSSIONS}

\section{The Effect of ISSECI Model on Thai EFL Students' Intercultural Pragmatic Competence}

Testing the hypothesis of the present study, t-test for dependent sample is adopted. The following statistic data shown in Table 2 below indicate the significant difference between pretest and posttest results.

According to table 2, the MEAN of participants' intercultural pragmatic competence after learning through ISSECI Model is 4.24 higher than that before the experiment. T-value is calculated as 16.71 with p-value 0.00 , which is lower than the alpha set at 0.05 . This infers the effectiveness of the innovative teaching, ISSECI Model confirmed by the significant increase of participants' intercultural pragmatic competence.

The perception of the participants with regard to enhancing their intercultural pragmatic competence through ISSECI Model regarding English knowledge, cultural aspects in English conversation, strength, and drawbacks of the model is revealed by the results of qualitative data analysis from unstructured interview can be presented in Table 3 below.

\section{Discussions}

The in-depth data after Table 3 assist elaborating how the innovative program has an effect on participants' learning intercultural pragmatic competence besides the statistic outcomes. In relation to English knowledge gained from the project, not only did the participants learn grammar and vocabulary, but they also realized how idioms and slangs play an important role in situational conversation. They admitted that many of these forms of languages were rarely introduced in the textbook they experiences in the former level of education, and they really needed learn and practice using such a domain of language use so that they can communicate more naturally as much as possible. Social factors are considered by the participants as the key factors influencing their decision on which form of language use they should select. The more distant the relation between them and their interlocutors became, the more formal forms of language tended to be employed as to show respect or realization of disturbance or face threatening. The pros of ISSECI Model involve encouraging the participants to think analytically of the proper communication in the international context they made a comparison between similarity and differences between Thai and non-Thai cultures of communication as well as principle of 'weightiness' including intimacy, seniority, and rank of imposition. Instead of giving explicit teaching, e.g., blunt explanation of the rules of language use and grammar, the participants were satisfied with the way the researcher taught implicitly, namely, giving sufficient samples of language forms prior to allowing them to find and summarize the rules of language use by themselves and challenging them to create their own style of language use while analyzing the appropriateness of such a form based on the theory they learned (Do FTA and Don't do FTA). Authentic learning is perceived as the interesting advantages of the model. The participants were assigned to submit the final report accumulating their asset of intercultural pragmatic knowledge. To gain this, they had to conduct a field trip study interviewing the foreigners from the different countries and cultural background of communication. This task provided them with a chance to learn and exchange the experiences or knowledge about communicative patterns between Thai and non-Thai in terms of politeness strategies. Also, through the authentic learning, the participants learned how to solve the intelligibility problems during the conversation with the foreigners. They struggled to use non-verbals, simplification of language use, exemplification, and so forth so that the interviewees could understand clearly what they tried to convey.

As for the weaknesses of the program, some participants did not achieve success in communicating with the foreign-

Table 2. Comparison between pretest and posttest results of participants' intercultural pragmatic competence - before and after learning through ISSECI model

\begin{tabular}{|c|c|c|c|c|c|c|}
\hline Test & n & Mean & Standard deviation & df & t-value & $p$-value \\
\hline Pretest & 20 & 11.78 & 1.69 & 19 & 16.71 & 0.00 \\
\hline Posttest & 20 & 16.02 & 1.58 & 19 & & \\
\hline
\end{tabular}


Table 3. The participants' perception towards enhancing their intercultural pragmatic competence through ISSECI model

\begin{tabular}{llll}
\hline English knowledge & Cultural aspects in English conversation & Strengths of ISSECI model & $\begin{array}{l}\text { Drawbacks of ISSECI } \\
\text { model }\end{array}$ \\
\hline - Expressions and & - Awareness of politeness & -Promoting critical thinking & -Difficulties in \\
vocabularies & - The importance of social factors affecting & -Extending language & $\begin{array}{l}\text { interviewing with } \\
\text { foreigners }\end{array}$ \\
- Grammars & the language use & knowledge through & -Time consuming \\
- Idioms and slangs & - Use of direct VS indirect form of & -Promoting critical thinking & -Extending language \\
& - Western culture VS Eastern culture language & knowledge through implicit \\
& use & learning & \\
& & -Learning differences between \\
& Thai and non-Thai way of \\
& communication & -Gaining more confidence \\
& & -Positive thinking towards \\
& English learning \\
& -Authentic learning: exchange \\
& & of knowledge and experiences \\
\hline
\end{tabular}

ers due to limited knowledge of idioms or vocabulary. Other spent such a longer time to find those expatriates or foreign tourists who were aware of the differences in English proficiency among Thais. As a results, they felt worried about completion of the task.

Converging with the findings of Thammaraksa (2010) and Onthanee (2008), the uncovered data pinpoint the role of university lecturer as a facilitator to support learners' knowledge management skill for better learning outcomes. As stated by Mikulecky and Mikulecka (1999), knowledge management can be simply applied to the university context, especially to promote the students' learning process by virtue of their desire to acquire knowledge from accessible sources.

\section{CONCLUSION}

As Thai EFL learners' insufficiency in intercultural pragmatic competence is claimed to be a problem which affects their intercultural communication in real life, this research was conducted to investigate the correlation between ISSECI Model and learners' achievement in using English in the context of intercultural communication as well as how it affects the participants' English learning experiences.

The findings of the current study indicates the potential of ISSECI model in reinforcing Thai EFL university learners' politeness strategies necessary significantly in communicating with foreigners. It can be concluded that the combination between second language acquisition (SLA) theory (Input Hypothesis and Scaffolding Technique) and knowledge management (KM) is another initial alternative for Thai educators. The program provides the learners with two session of self-directed learning atmosphere. Session one the theory and practice relying on comprehensible input or contents and rules together with critical thinking promotion and problem-solving skill practice systematically. The other session is applying KM to learning cultural norms and accumulating the tacit knowledge from various sources or related person, i.e., peers' previous experiences, foreigners, websites, etc., before sharing what they learn with the others.
This method is believed to help the learners maintain their knowledge asset for effective future intercultural pragmatic competence in real life situations.

\section{END NOTE}

1. After the findings of the study on 'Requesting and Request Refusing in Thai” (Deepadung and Khamhirun, 2005), to redress the curt form of language, politeness strategies such as, address terms (calling the hearers by their names before revealing the request), final particles (e.g./^na/), and polite final particles (e.g./_ $\kappa^{\mathrm{h}} \alpha /$ are widely used.)

\section{REFERENCES}

Alptekin, C. (2002). "Towards intercultural communicative competence in ELT.” ELT Journal 56 (1): 57-64.

Bachman, L.F. and A.S. Palmer. (1996). Language Testing in Practice: Designing and Developing Useful Language Tests. Oxford: OUP.

Bardovi-Harlig, K. and B. S. Hartford. (1993). "Learning the rules of academic talk: A longitudinal study of pragmatic change." Studies in Second Language Acquisition, 15: 279-304.

Blum-Kulka, S. and E. Olshtain. (1986). "Too many words: Length of utterance and pragmatic failure." Studies in Second Language Acquisition 8: 165-179.

Bouton, L. F. (1994a). "Conversational implicature in a second language: Learned slowly when not deliberately taught." Journal of Pragmatics 22: 157-167.

Bowe, H. and K. Martin. (2007). Communication across cultures: mutual understanding in a global world. Melbourne: Cambridge University Press.

Bransford, J., A. Brown, and R. Cocking. (2000). How People Learn: Brain, Mind, and Experience \& School.

Washington, DC: National Academy Press.

Brislin, R. (1997). "Introducing active exercises in the college classroom for intercultural and cross-cultural courses." In Cushner, K. and Brislin, R. Improving Intercul- 
tural Interactions 2. Thousand Oaks, California: Sage Publication, 301-315.

Brown, P. and Levinson, S. (1987). Politeness: Some Universals in Language Usage. Cambridge: Cambridge University Press.

Chang, K., I. Chen, and Y. Sung. (2002). "The effect of concept mapping to enhance text comprehension and summarization." The Journal of Experimental Education 71 (1): 5-23.

Chayanuvat, A. (2007). Developing a PBL English course: $A$ discovery journey. Paper presented at the Third International Conference on PBL, Nakhon Si Thammarat, Thailand.

Chiravate, B. (2011). Perception of politeness in English requests by Thai EFL learners. 3L; Language, Linguistics and Literature, The Southeast Asian Journal of English Language Studies 7 (2): 59-71.

Cohen, E.G. (1994). "Restructuring the classroom: Conditions for productive small groups." Review of Educational Research 64: 1-35.

Damnet, A. (2008). Enhancing Acquisition of Intercultural Nonverbal Competence: Thai English as a Foreign Language Learners and the Use of Contemporary English Films. Unpublished Doctoral of Philosophy Thesis in

Communication and the Arts. Victoria University.

Deepadung, S. (2009). Introduction to Pragmatics. Bangkok: Samlada Ltd., Part.

Deepadung, S. and S. Khamhirun. (2005). Requests and Refusal of Requests in Thai. Research report, Research Institute for Languages and Cultures of Asia Mahidol University.

Ellis, R. (1999). "Making the classroom acquisition-rich." In R. Ellis (ed.). Learning a second language through interaction. Amsterdam: John Benjamins, 211-229.

Goffman, E. (1967). Interaction ritual: Essay in Face-toFace Behaviour. Chicago: Aldine Publishing Company.

Harrison, R. P., A.A. Cohen, W.W. Crouch, B.K.L. Genova, and M. Steinberg. (1972). "The Nonverbal communication Literature." Journal of Communication 22: 460-476.

Higgenbotham, J.B. and K.K. Cox. (ed.). 1979. Focus group interviews: A reader. Chicago: American Marketing Association.

Intaraprawat, P. (1978). English Teaching Methods. Songkhla: Srinakharinwirot University, Songkhla.

Janney, R.W. and H. Arndt. (2003). "Universality and relativity in cross-cultural politeness research: a historical perspective." Multilingua 12: 13-50.

Jenkins, J. (1996). "Native Speaker, Non-native Speaker and English as a Foreign Language: time for a change." IATEFL Newsletter 131: 10-11.

Khahua, J. (2003). A study of speech act patterns of requests in Thai society. Master of Arts Thesis in Linguistics. Mahidol University.

Khamkhien, A. (2010). "Factors affecting language learning strategy reported usage by Thai and Vietnamese EFL learners." Electronic Journal of Foreign Language Teaching 7 (1): 66-85.
Khamyod, T. and P. Aksornjarung. (2011). "A Comparative Study of Pragmatic Competence of Learners with High and Low English Proficiency." $3^{\text {rd }}$ International Conference on Humanities and Social Sciences April 2, 2011.

Faculty of Liberal Arts, Prince of Songkla University. Proceedings-English Studies in Various Contexts: 1-15.

Khanittanan, W. (1988). "Some observations on expressing politeness in Thai."Language Science 10 (2): 353-362.

Kirkpatrick, A. (2007). World Englishes. Implications for International Communication and English Language Teaching, Cambridge, Cambridge University Press.

Krashen, S.D. (1981). Second Language Acquisition and Second Language Learning. Oxford: Pergamon.

Krashen, S.D. (1985). The Input Hypothesis: Issues and Implications. New York: Longman.

Krashen, S.D. and Terrell, T. (1983). The Natural Approach: Language acquisition in the classroom. Oxford: Pergamon.

McKenzie, J. (2000). "Scaffolding for Success." Beyond Technology, Questioning, Research and the Information

Literate School Community. Retrieved May 5, 2015 from. http://fno.org/dec99/scaffold.html

Mikulecky, P. and Mikulecka, J. (1999). “Active Tools for Better Knowledge Dissemination", ASIS 1999 Annual Meeting, Washington D.C., 420-427

Myhill, D.J.S. and A. Watson. (2012). "Re-thinking grammar: the impact of embedded grammar teaching on students' writing and students' metalinguistic understanding." Research Paper in Education. 2 (27):139-166.

Nonaka, I. and H. Takeuchi. (1995). The knowledge-creating company. New York, Oxford: Oxford University Press.

Olson, J. and J. Platt. (2000). "The Instructional Cycle." Teaching Children and Adolescents with Special Needs. Upper Saddle River, NJ: Prentice-Hall, Inc., 170-197.

Onthanee, A. (2008). The development of the instructional model to enhance learning facilitator's competence based on knowledge management approach for teacher students. Doctor of Education Thesis in Curriculum and Instruction. Naresuan University.

Pinyo, S. (2010). Pragmatic Competence in Requests: A Case of Thai English Teacher. Master of Arts Thesis in teaching English as an International Language. Prince of Songkhla University.

Pinyo, S., P. Aksornjarung, and C. Laohawiriyanon. (2010). "Pragmatic competence in requests: A case study with Thai English teachers." Proceedings of the $2^{\text {nd }}$ International Conference on Humanities and Social Sciences. Songkla, Thailand.

Poonpon, K. (2011). "Enhancing English Skills through Project Based Learning."'In The English Teacher, XL (1-10). Retrieved April 10, 2013 from www.elta.org.my/ ET/201/1_10_Kornwipa\%20201.pdf

Prasansap, W. (1999). English teaching behaviour, academic Rajabhat publication in honor of His Majesty King Bhumibol's $72^{\text {nd }}$ birthday celebration. Petchaburi: Petchaburi Rajabhat Institute.

Raymond, E. (2000). "Cognitive Characteristics.” Learners with Mild Disabilities. Needham Heights, MA: Allyn \& Bacon, A Pearson Education Company, 169-201. 
Skutnabb-Kangas, T. (2000). Linguistic Genocide in Education-or Worldwide Diversity and Human Rights? Mahwah NJ: Lawrence Erlbaum.

Stewart, D.W., P.N. Shamdasani, and D.W.Rook. (2007). Focus groups: Theory and Practices. $2^{\text {nd }}$ ed. Thousand Oaks, CA: Sage.

Thammaraksa, C. (2010). "Innovative English Teaching by Using SECI Model.” BU Academic Review 9 (2): 79-91.

The ASEAN Secretariat. (2008). The ASEAN Charter. Jarkarta: Indonesia.

Trenholm, S. and A. Jensen. (2004). Interpersonal Communication. $5^{\text {th }}$ ed. New York: Oxford University Press.

Ungureanu, S. (2004). "Euphemisms. Studia Universitatis Babes-Bolyai.” Philologia 49 (1): 127-139.
Vygotsky, L. (1978). Mind in society: The developmental of higher psychological process. Cambridge MA: Harvard University Press.

Watts, R. (2003). Politeness. Cambridge: Cambridge University Press.

Wongsothorn, A. (2000). "Thailand." In H. W. Kam \& R. Y. L. Wong (eds.). Language policies and language education: The impact in East Asian countries in the next decade. Singapore: Times Academic Press, 307320.

Wood, D., J. Bruner, and G. Ross. (1976). "The role of tutoring in problem-solving." In Journal of Child Psychology and Psychiatry 17 (2): 89-100. 